\title{
Factors Affecting Growth and Pigmentation of Penicillium caseifulvum
}

\author{
K. I. Suhr, I. Haasum, L. D. Steenstrup, and T. O. Larsen \\ Mycology Group, Biocentrum-DTU, \\ Søltofts Plads, Building 221, \\ Technical University of Denmark, \\ DK-2800 Lyngby, Denmark
}

\section{ABSTRACT}

Color formation, metabolite production and growth of Penicillium caseifulvum were studied in order to elucidate factors contributing to yellow discoloration of Blue Cheese caused by the mold. A screening experiment was set up to study the effect of $\mathrm{pH}$, concentration of salt $(\mathrm{NaCl}), \mathrm{P}, \mathrm{K}, \mathrm{N}, \mathrm{S}, \mathrm{Mg}$ and the trace metals $\mathrm{Fe}, \mathrm{Cu}, \mathrm{Zn}, \mathrm{Mn}$ on yellow color formation, metabolite production and mold growth. Multivariate statistical analysis showed that the most important factor affecting yellow color formation was $\mathrm{pH}$. The most pronounced formation of yellow color, supported by highest amount of colored metabolites, appeared at low $\mathrm{pH}(\mathrm{pH}$ 4). Mold growth was not correlated to the yellow color formation. Salt concentration was the most important factor affecting mold growth and length of lag phase. Production of secondary metabolites was strongly influenced by both $\mathrm{pH}$ and salt concentration. The screening results were used to divide the metabolites into the following three groups: 1) correlated to growth, 2) correlated to color formation, and 3) formed at high $\mathrm{pH}$. Subsequently, a full factorial experiment with factors $\mathrm{P}, \mathrm{Mg}$ and $\mathrm{Cu}$, showed that low $\mathrm{P}$ concentrations (2000 $\mathrm{mg} / \mathrm{kg}$ ) induced yellow color formation. Among the factors contributing to yellow color formation, $\mathrm{pH}$ and salt concentration are easy to control for the cheesemaker, while the third factor, P-concentration, is not. Naturally occurring variations in the $\mathrm{P}$-concentration in milk delivered to Blue Cheese plants, could be responsible for the yellow discoloration phenomenon observed in the dairy industry.

(Key words: blue cheese, Penicillium caseifulvum, pigmentation)

Abbreviation key: $\mathbf{a}_{\mathbf{w}}=$ water activity, $\mathbf{H P L C}=$ High performance liquid chromatography, $\mathbf{P L S}=$ partial least square regression.

Received March 15, 2002.

Accepted June 25, 2002.

Corresponding author: Karin Isabel Suhr; e-mail: kasu@ biocentrum.dtu.dk.

\section{INTRODUCTION}

Penicillium caseifulvum is a recently described species isolated from Roqueforti-fermented cheese types, i.e. blue cheese, and their production environment (Lund, 1998). Experiments have shown that metabolites produced by $P$. caseifulvum are responsible for yellowish spots appearing on the surface of these cheeses (Lund, 1995). Although the mold is present and grows in the environment and on the cheese all year round, the discoloration only appears in certain periods, and is most pronounced in the summer. This suggests that unknown factors in the cheese control the production of the colored metabolites. Although discoloration of cheese by contaminating molds has been previously described (Chapman and Sharpe, 1990; Estrup, 1994; Piantanida et al., 1995), knowledge of the biochemical mechanisms and essential factors for discoloration is limited.

Cheese contains all the essential nutrients for growth of fungi (Northolt et al., 1995). However, the proportions of nutrients in the cheese will depend upon the production process, such as coagulation, whey removal, and salting (Martin-Hernández et al., 1992; Coni et al., 1995). As process parameters are held relatively constant when making a specific cheese type, variability in the mineral content of the cheese is mainly due to changes in the milk. In modern dairying, feeding practice is the most important factor for variability, and this is normally linked with season. The greatest seasonal effect occurs in the spring-summer, when cows are fed fresh grass (Grandison et al., 1984; Mariani et al., 1993). Grazing correlates with higher $\mathrm{pH}$ in the milk, due to a changed balance of salts (Hermansen et al., 1994). Variability of soluble inorganic phosphorus is the main contributor to changes in the salt balances (Donnelly and Horne, 1986). The concentration of $\mathrm{Cu}$ in the milk is lowest in the summer, while $\mathrm{Zn}$ and $\mathrm{Fe}$ are reported to have the highest level during this time of the year (von Kreuzer and Kirchgessner, 1990; Larsen and Werner, 1985). Generally, the lowest levels of minerals in the milk occur from April to September (in Denmark), with changes between 5 and 10\% (Larsen and Werner, 1984), coinciding with grazing of cows. The 
amount of minerals in vat milk is not standardized prior to cheese making, and as a result mineral levels in blue cheese fluctuate according to the natural variation in the raw milk.

Growth of fungi depends on the composition of the growth media, water activity $\left(\mathbf{a}_{\mathbf{w}}\right), \mathrm{pH}$, temperature, light, and the surrounding atmospheric gas mixture. The effect of environmental factors on growth of fungi is generally less specific and restricted than the effect on secondary metabolite production. For example, the ranges of $\mathrm{a}_{\mathrm{w}}$ and $\mathrm{pH}$ within which formation of certain secondary metabolites occur, is more narrow, than the range for conidial growth (Northolt and Bullerman, 1982).

The effect trace elements such as $\mathrm{Zn}, \mathrm{Cu}, \mathrm{Fe}$, and $\mathrm{Mn}$ have on the secondary metabolism of fungi has been investigated (Smith, 1949; Francis, 1985; Griffin, 1994). For example, production of the yellow pigment citrinin, by Penicillium implicatum, was induced by addition of $\mathrm{Cu}$ and $\mathrm{Zn}$ to the growth media (Smith, 1949), and other minerals have been reported to be involved in the formation of other pigments (Francis, 1985).

The purpose of this study was to determine the effect of $\mathrm{pH}$, salt, and selected minerals on the growth and pigmentation of $P$. caseifulvum.

\section{MATERIALS AND METHODS}

\section{Organisms and Preparation of Inoculum}

Two isolates of Penicillium caseifulvum (IBT 15151 ex. Danablu, DK and IBT 15157 ex. Danablu, DK), obtained from the culture collection at Biocentrum-DTU, Technical University of Denmark, originating from two different dairy plants, were used for the experiments. Conidiated cultures were prepared by spreading silicadried spores on Czapeck Yeast autolysate Agar (Pitt, 1979) with modifications (Samson et al., 1995). Plates were incubated for $7 \mathrm{~d}$ at $25^{\circ} \mathrm{C}$ in the dark, after which colonies were transferred to fresh media and reincubated for $7 \mathrm{~d}$ under the same conditions. Suspensions of spores for inoculation were made as $10^{6}$ spores $/ \mathrm{ml}$ in double distilled water with $0.5 \%$ agar and $0.5 \%$ Tween-80.

\section{Media Preparation}

Media for the experiments were modified from inorganic Raulin-Thom (RT) media, which was modified from Clutterbuck et al. (1932). Salt ( $\mathrm{NaCl})$ content and $\mathrm{pH}$ of the media was varied from 3 to $10 \%(\mathrm{w} / \mathrm{w})$ and from 4 to 6 , respectively. Adjustment of $\mathrm{pH}$ was done prior to autoclaving by adding $\mathrm{HCl}$ or $\mathrm{NaOH}$. The minerals varied in the media were $\mathrm{P}, \mathrm{K}, \mathrm{Mg}, \mathrm{Fe}, \mathrm{Cu}, \mathrm{Zn}$ and $\mathrm{Mn}$, and their concentrations ranged from 2000 to
$6000 \mathrm{mg} / \mathrm{kg}$ (ppm) for $\mathrm{P}\left(\left(\mathrm{NH}_{4}\right)_{2} \mathrm{HPO}_{4}\right), 500$ to $3000 \mathrm{ppm}$ for $\mathrm{K}(\mathrm{KCl}), 150$ to $300 \mathrm{ppm}$ for $\mathrm{Mg}\left(\mathrm{MgSO}_{4} \cdot 7 \mathrm{H}_{2} \mathrm{O}\right)$, 0.5 to $3 \mathrm{ppm}$ for $\mathrm{Fe}\left(\mathrm{FeSO}_{4} \cdot 7 \mathrm{H}_{2} \mathrm{O}\right), 0.3$ to $1.5 \mathrm{ppm}$ for $\mathrm{Cu}\left(\mathrm{CuSO}_{4} \cdot 5 \mathrm{H}_{2} \mathrm{O}\right), 30$ to $250 \mathrm{ppm}$ for $\mathrm{Zn}\left(\mathrm{ZnSO}_{4} \cdot\right.$ $\mathrm{H}_{2} \mathrm{O}$ ), and 0.3 to $10.6 \mathrm{ppm}$ for $\mathrm{Mn}\left(\mathrm{MnSO}_{4} \cdot \mathrm{H}_{2} \mathrm{O}\right)$. All chemicals were from Merck (Darmstadt, Germany), except Zn, which was from Sigma Chemicals (St. Louis, MO). The mineral ranges used correspond to the typical range of these minerals in Danablu cheese 50+ (National Food Agency of Denmark, 1989). All minerals were dissolved in water and added as water solutions to the media. Besides the minerals, all media contained 0.26\% ammonium(+)tartrate (BDH Chemicals, Poole, England), $0.26 \%$ L(+)tartaric acid (Merck), $5 \%$ $\mathrm{D}(+)$ glucose (BDH) and $2 \%$ agar (B\&B, Rødovre, Denmark). Agar, glucose and water were autoclaved in a separate mixture to avoid acid hydrolysis of the agar and Maillard reactions.

\section{Inoculation and Incubation}

The prepared media were inoculated with spore suspension in three points with a needle. Two Petri dishes of each medium were covered with adhesive autoclavable cellophane for later evaluation of reverse colony color. Cellophane-covered plates were inoculated with a droplet of $10 \mu \mathrm{l}$ spore suspension. Fungi were cultured at $25^{\circ} \mathrm{C}$ in the dark for a 3 -wk period.

\section{Experimental Design}

A 2-level fractional factorial design $\left(1 / 2^{5} \times 2^{9}\right)$ with three center points was constructed for testing the nine factors: $\mathrm{pH}$, salt, $\mathrm{P}, \mathrm{K}, \mathrm{Mg}, \mathrm{Fe}, \mathrm{Cu}, \mathrm{Zn}$ and $\mathrm{Mn}$ (Table 1). The design yielded 17 different media. Subsequently, a full factorial experiment $\left(2^{3}\right)$ with three center points was designed to investigate further the factors: $\mathrm{P}, \mathrm{Cu}$ and $\mathrm{Mg}$. The ranges of $\mathrm{P}, \mathrm{Cu}$ and $\mathrm{Mg}$ in the media were identical to those in the screening experiment while the other factors were held constant at the center point values from the screening experiment, except salt, which was added in the amount of $3 \%(\mathrm{w} / \mathrm{w})$. The design yielded eight different media. All experiments were designed using the software program Modde version 3.0 (Umetri AB, Umeå, Sweden).

\section{Colony Measurements}

The colony diameter was recorded (in millimeters) after $3,7,10$, and $14 \mathrm{~d}$ of incubation. The mean of six colony measurements was used for data analysis. The lag phase was defined as the number of days until the colony diameter exceeded $2 \mathrm{~mm}$.

The color was measured on both the front (obverse) and reverse side of the mold colony. Color measure- 
Table 1. Screening experiment for Penicillium caseifulvum growth and color formation on media with different $\mathrm{pH}$ levels and different concentrations of salt and minerals.

\begin{tabular}{|c|c|c|c|c|c|c|c|c|c|}
\hline \multirow[b]{2}{*}{ Media } & \multirow[b]{2}{*}{$\mathrm{pH}^{1}$} & \multirow[b]{2}{*}{ Salt \% } & \multicolumn{7}{|c|}{ Mineral content of the media, $\mathrm{ppm}(\mathrm{mg} / \mathrm{kg})$} \\
\hline & & & $\mathrm{Mg}^{2}$ & $\mathrm{Fe}^{2}$ & $\mathrm{~K}^{3}$ & $\mathrm{P}^{4}$ & $\mathrm{Cu}^{2}$ & $\mathrm{Zn}^{2}$ & $\mathrm{Mn}^{2}$ \\
\hline N1 & 4.4 & 3 & 150 & 0.50 & 500 & 2000 & 0.3 & 30 & 0.60 \\
\hline N2 & 6.4 & 3 & 150 & 0.50 & 3000 & 2000 & 1.5 & 250 & 0.30 \\
\hline N3 & 4.4 & 10 & 150 & 0.50 & 3000 & 6000 & 0.3 & 250 & 0.30 \\
\hline N4 & 6.4 & 10 & 150 & 0.50 & 500 & 6000 & 1.5 & 30 & 0.60 \\
\hline N5 & 4.4 & 3 & 300 & 0.50 & 3000 & 6000 & 1.5 & 30 & 0.30 \\
\hline N6 & 6.4 & 3 & 300 & 0.50 & 500 & 6000 & 0.3 & 250 & 0.60 \\
\hline N7 & 4.4 & 10 & 300 & 0.50 & 500 & 2000 & 1.5 & 250 & 0.60 \\
\hline N8 & 6.4 & 10 & 300 & 3.00 & 3000 & 2000 & 0.3 & 30 & 0.30 \\
\hline N9 & 4.4 & 3 & 150 & 3.00 & 500 & 6000 & 1.5 & 250 & 0.30 \\
\hline N10 & 6.4 & 3 & 150 & 3.00 & 3000 & 6000 & 0.3 & 30 & 0.60 \\
\hline N11 & 4.4 & 10 & 150 & 3.00 & 3000 & 2000 & 1.5 & 30 & 0.60 \\
\hline N12 & 6.4 & 10 & 150 & 3.00 & 500 & 2000 & 0.3 & 250 & 0.30 \\
\hline N13 & 4.4 & 3 & 300 & 3.00 & 3000 & 2000 & 0.3 & 250 & 0.60 \\
\hline N14 & 6.4 & 3 & 300 & 3.00 & 500 & 2000 & 1.5 & 30 & 0.30 \\
\hline N15 & 4.4 & 10 & 300 & 3.00 & 500 & 6000 & 0.3 & 30 & 0.30 \\
\hline N16 & 6.4 & 10 & 300 & 3.00 & 3000 & 6000 & 1.5 & 250 & 0.60 \\
\hline N17 & 5.4 & 6.5 & 225 & 1.75 & 1750 & 4000 & 0.9 & 140 & 0.45 \\
\hline N18 & 5.4 & 6.5 & 225 & 1.75 & 1750 & 4000 & 0.9 & 140 & 0.45 \\
\hline N19 & 5.4 & 6.5 & 225 & 1.75 & 1750 & 4000 & 0.9 & 140 & 0.45 \\
\hline
\end{tabular}

${ }^{1}$ The exact $\mathrm{pH}$ value of each media was measured after autoclaving and used for data analysis.

${ }^{2}$ Added as sulfate salts.

${ }^{3}$ Added as chloride salt.

${ }^{4}$ Added as di-ammonium hydrogen-phosphate salt.

ments of the reverse were done using the cellophanecovered plates. The cellophane was removed, thereby separating the mycelium from the agar surface, uncovering the reverse side of the colony. Color was measured with a colorimeter (Croma Meter, CCR-200, Minolta, Japan) as $\mathrm{L}^{*}, \mathrm{a}^{*}$ and $\mathrm{b}^{*}$ values, which, going from low to high numbers, measures the color spectra as follows: black to white $\left(\mathrm{L}^{*}\right)$, green to red $\left(\mathrm{a}^{*}\right)$ and blue to yellow $\left(b^{*}\right)$. In order to use values that better described colony colors, $\mathrm{L}^{*}$ and $\mathrm{b}^{*}$ values were referred to as lightness and yellow color, respectively. Measures of a* were reversed, so the spectra, going from high to low numbers, described red to green, and thus a* was referred to as green color. Measurements were performed after $14 \mathrm{~d}$ of incubation. The mean of triplicate measurements was used for data analysis.

\section{Extraction and Analysis of Metabolites}

Fungal biomass from 21-d-old colonies (from the screening experiment only) was extracted with a mixture of $50 \mathrm{ml}$ methanol, dichloromethane and ethyl acetate in the proportion 3:2:1 and added $0.5 \%$ formic acid. The organic extract was filtered through a Whatman 1 PS phase separator filter and evaporated on a rotary evaporator to dryness. The residue was dissolved in $1.5 \mathrm{ml}$ methanol and transferred to a vial through a Minisart RC 15 filter $(0.45 \mu \mathrm{m})$ before analysis. The extracts were analyzed by reverse-phase high-perfor- mance liquid chromatography (HPLC) on a Hewlett Packard 1090 series II liquid chromatograph (Hewlett Packard, Germany) with a built-in diode array detector measuring full UV-VIS spectra (200 to $600 \mathrm{~nm}$ ) for each peak detected at 210 and $340 \mathrm{~nm}$. The gradient ran from $15.0 \%$ acetonitrile (Merck 707) in water to $100 \%$ acetonitrile, and contained $0.005 \%$ trifluoracetic acid (Merck 633). It was held at a flow rate of $1 \mathrm{ml} / \mathrm{min}$. The column was a $4 \mathrm{~mm}$ id $\times 100 \mathrm{~mm}$ HP Hypersil BDS C18 (3 $\mu \mathrm{m}$ particles).

Metabolites were quantified by peak area (milliabsorption units $(\mathrm{mAu}) \times \mathrm{s})$ at $\lambda_{\max }$, or maximum absorption $(\mathrm{mAu})$ if interfering substances were found within the area. The peak area of ergosterol in the samples, which is a suitable measure of mold growth (Seitz et al., 1979), was measured and used for standardizing the metabolite content according to biomass units. Retention indices (RI) of fungal metabolites were calculated according to Frisvad and Thrane (1987).

\section{Response Variables and Data Analysis}

The response variables in the screening experiment, 17 in all, were the following: mold diameter recorded after 7 and $14 \mathrm{~d}$, the calculated lag phase, color coordinates (i.e. $L^{*}, a^{*}$, and $b^{*}$ values) for obverse and reverse sides of the colony, and finally eight metabolites were quantified and used for analysis. In the subsequent full-factor experiment, the metabolite extraction was 
omitted, and only colony diameter after $14 \mathrm{~d}$ and reverse side color coordinates were used for analysis, thus four responses were used for analysis.

The data were analyzed by partial least square (PLS) regression using SIMCA-P for Windows (version 2.1, 1995; Umetri AB, Umeå, Sweden). We previously described the advantages of using this method for physiological characterization of fungi (Haasum and Nielsen, 1998). The statistical principle of the method was described by Wold et al. (1984). The X-matrix for the screening experiment consisted of the design variables given in Table 1 . All minerals except $\mathrm{P}$ were added to the media as sulfate compounds, and in order to determine the effect of sulfate, it was added to the matrix as an uncontrolled variable ( $\mathrm{P}$ was added as an ammonia compound to the media, and since this was the only mineral added as such, the effect of ammonia was completely confounded with P).

Prior to statistical analysis, all variables were standardized to mean zero and variance one. In the screening experiment the two $P$. caseifulvum isolates responded alike, thus only one representative is shown in the figures, whereas for the full factor experiments, results for both isolates are shown.

\section{RESULTS AND DISCUSSION}

\section{Secondary Metabolites}

Seven chromophores represented the majority of the metabolites in all mold extracts. As the examples of chromatograms for media N10 and N13 show, the seven metabolites were not all present in all extracts (Figure 1). For example, N10 supported low metabolite F production and high metabolite I, whereas the opposite was true for media N13. Metabolite D had two analog forms, which were called D1 and D2. Using results from Frisvad and Thrane (1987) the metabolites B and C were identified as rugulovasine and cyclopeptine, respectively. The chemical structures of the other metabolites (i.e. A, D1, D2, E, F and I) were not identified.

Strong absorption of light was detected for metabolites $\mathrm{E}$ and $\mathrm{F}$ in the visible wavelength area (380 to $780 \mathrm{~nm}$ ), indicating that these metabolites were colored products (Figure 2). The spectrum of metabolite $\mathrm{F}$ showed especially strong absorption at 350 to $500 \mathrm{~nm}$ indicating a yellow to orange-yellow color, while metabolite $\mathrm{E}$ absorbed at 350 to $420 \mathrm{~nm}$, indicating a more greenish-yellow color (Figure 2). Metabolites D1 and D2 had slight absorption above $380 \mathrm{~nm}$, indicating that these might have some coloring properties (Figure 2). The remaining metabolites (A, rugulovasine, cyclopeptine and I) did not absorb light in the visible wavelength area.

All metabolites were quantified at the wavelength where peak absorbance was observed. In this fashion, the metabolites A, rugulovasine, cyclopeptine, and ergosterol (used as a biomass indicator) were quantified in chromatograms obtained at $210 \mathrm{~nm}$; metabolites $\mathrm{D} 1, \mathrm{D} 2$, and I were quantified at $335 \mathrm{~nm}$, while E was quantified at $400 \mathrm{~nm}$. Detachment of metabolite $\mathrm{F}$ from

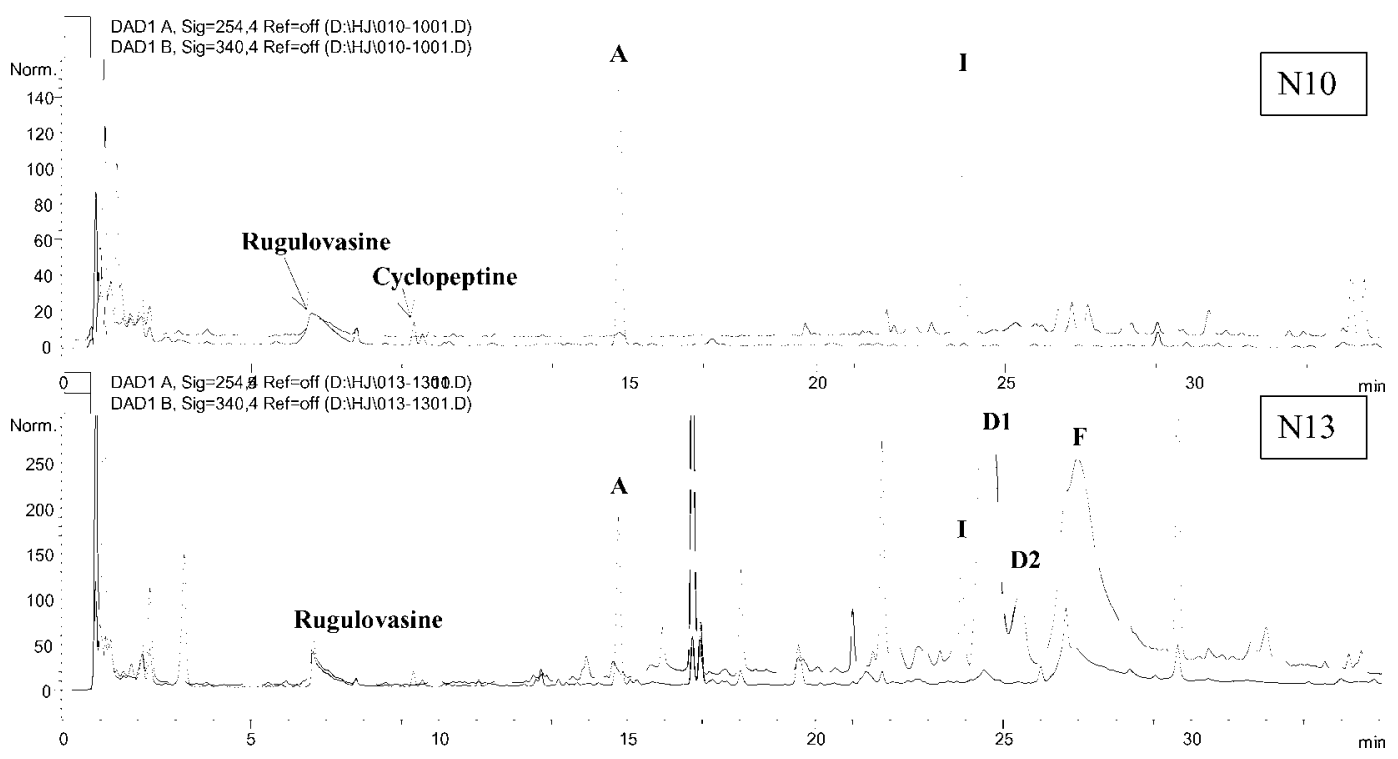

Figure 1. Chromatograms of Penicillium caseifulvum (IBT 15151) on media N10 and N13 obtained at $254 \mathrm{~nm}$ (full line) and $340 \mathrm{~nm}$ (dashed line). Metabolites A, B (rugulovasine), C (cyclopeptine), D1, D2, E, F, and I were quantified for statistical analysis (metabolite E was not produced on the media shown here). Norm: Normalized absorption in milliabsorption units. 

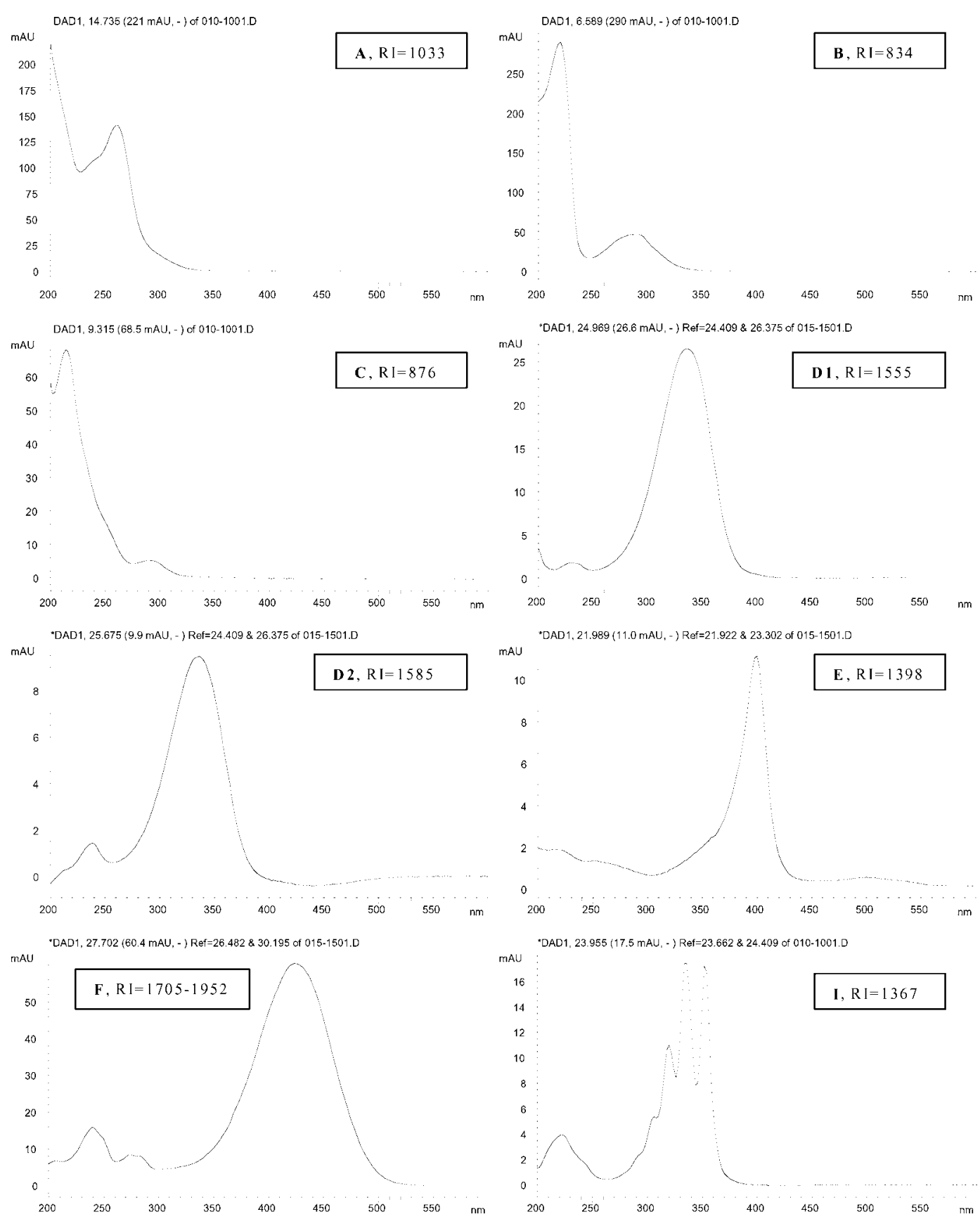

Figure 2. UV-spectra and retention index (RI) of metabolites from Penicillium caseifulvum. Metabolites E and F showed absorption of light in the visible area (380 to $780 \mathrm{~nm})$. mAU: milliabsorption units.

the column was not optimal, causing a broad peak and a span in the retention index. In order to reduce interference from other substances, it was quantified at $432 \mathrm{~nm}$.

\section{Effect of Salt and pH on Growth and Color of $P$. caseifulvum}

Growth of $P$. caseifulvum was strongly correlated with salt content of the media. On media with $10 \%$ salt, the average mold colony diameter was $8.4 \pm 3.5 \mathrm{~mm}$ after $2 \mathrm{wk}$, whereas on media containing $3 \%$ salt, it averaged $38.4 \pm 8.8 \mathrm{~mm}$ (Figure $3 \mathrm{a}$ ). Measurements of reverse yellow color (reverse b) correlated well with $\mathrm{pH}$ values of the media (Figure 3b). At $\mathrm{pH} 4$ the $\mathrm{b}$ average was $44.0 \pm 7.7$, while at $\mathrm{pH} 6$ it was $14.0 \pm 8.2$. Thus at low $\mathrm{pH}$ the reverse colony color of $P$. caseifulvum was more yellow compared with high $\mathrm{pH}$. Production of metabolite $\mathrm{F}$ also followed this pattern, so that the 
a.

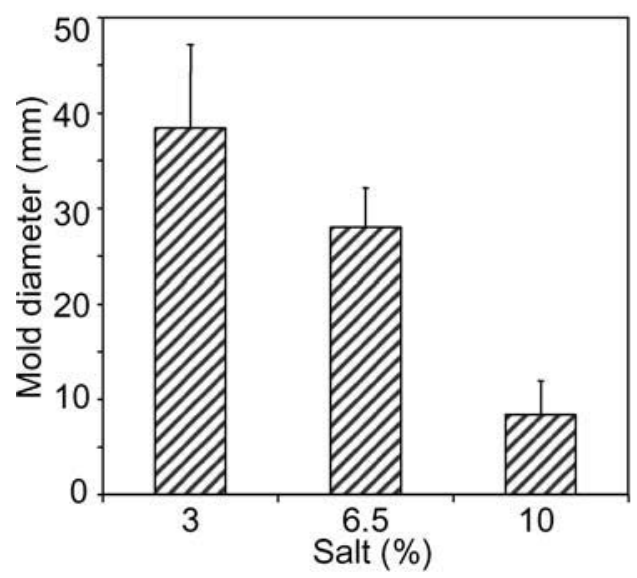

b.

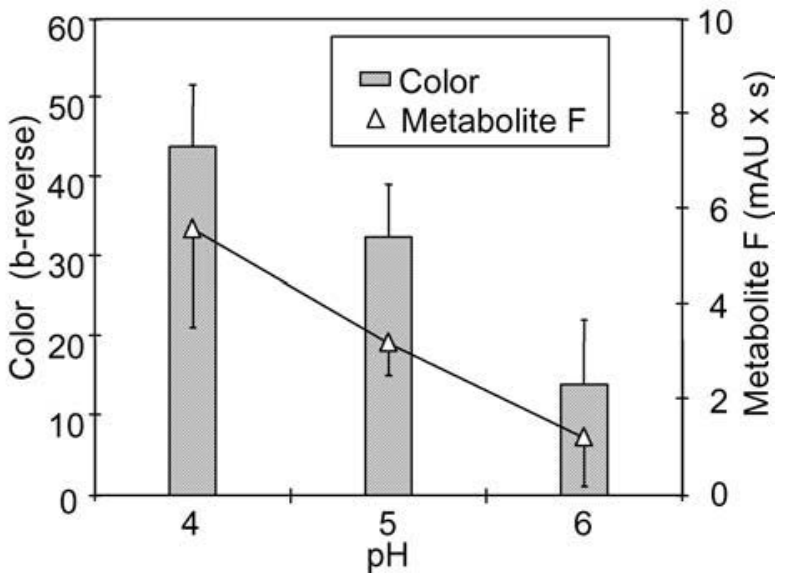

Figure 3. Salt content in the media correlated to measurements of growth (a), and $\mathrm{pH}$ correlated to measurements of yellow color (coordinate b on the Chroma Meter) and production of metabolite F (b).

mean production of metabolite $\mathrm{F}$ was $5.6 \pm 2.0$ and 1.2 $\pm 1.0 \mathrm{mAu} \times \mathrm{s}$ on media with $\mathrm{pH} 4$ and 6 , respectively. Thus, metabolite $\mathrm{F}$ could be used as a measure of yellow color development of $P$. caseifulvum colonies. It should be noted, that all extractions were performed at identical $\mathrm{pH}$ values (in $0.5 \%$ formic acid), thus the observed correlation between $\mathrm{pH}$ and yellow color was not caused by any extra-cellular $\mathrm{pH}$ effect.

The PLS model obtained by statistical analysis consisted of four significant components, explaining 70.4\% of the variation in the data. Loading component one showed that salt was positively correlated with lag phase, and negatively correlated with growth (colony diameter), and production of rugulovasine, cyclopeptine, and metabolite A (Figure 4a). Thus, high salt content in the media produced longer lag phase, less mold growth, and inhibited production of some metabolites. Extension of lag phase caused by high salt percent is well known for P. roqueforti (Godinho and Fox, 1981). Furthermore, high salt-media produced less green and more white colony obverse colors, which agreed with the fact that mold growth was reduced in high salt media, resulting in fewer conidia and consequently less green color.

Loading component two showed the strong negative correlation between reverse yellow color and $\mathrm{pH}$ (Figure 4a), which was described earlier. Obverse yellow and reverse lightness were also negatively correlated with $\mathrm{pH}$ and thus positively correlated with reverse yellow. This suggests that measuring the colony color of the obverse side of $P$. caseifulvum gives a good indication of the yellowness on the reverse. Visually observed color of the reverse also showed the $\mathrm{pH}$ effect, as groupings of yellow and orange-yellow colonies appeared in media with low $\mathrm{pH}(4)$, as indicated in the score-plot
(Figure 4b). This observation was notable after $7 \mathrm{~d}$, and very clear after $21 \mathrm{~d}$.

Media $\mathrm{pH}$ was also negatively correlated with production of metabolites D1, D2, E, and F (Figure 4a). Thus low $\mathrm{pH}$ (4) induced production of these metabolites. Component two also described production of metabolite I, however, contrary to the other metabolites, production of I was stimulated at high $\mathrm{pH}$.

Overall, the model divided the metabolites into three groups: 1) rugulovasine, cyclopeptine and metabolite A, which were associated with mold growth;2) metabolites $\mathrm{D} 1, \mathrm{D} 2, \mathrm{E}$ and $\mathrm{F}$, which were associated with low $\mathrm{pH}$ and yellow color; and 3) metabolite I, which was associated with high $\mathrm{pH}$ values. It is likely that there is a biosynthetic relationship between metabolites D1 and $\mathrm{D} 2$ and metabolite $\mathrm{F}$ because of the similarities in their UV-spectra (Figure 2) and their loading values in the PLS model (Figure 4a).

\section{Effect of Minerals on Growth and Color of $P$. caseifulvum}

All media except N3 supported mold growth. This medium had a $\mathrm{pH}$ of $4,10 \%$ salt, low content of $\mathrm{Fe}$ $(0.5 \mathrm{mg} / \mathrm{kg}), \mathrm{Cu}(0.3 \mathrm{mg} / \mathrm{kg})$ and $\mathrm{Mn}(150 \mathrm{mg} / \mathrm{kg})$; this combination of ingredients may have caused the lack of mold growth. However, the PLS loading plot showed that the effects of minerals on mold growth, color and metabolite production were small or insignificant (all loading values of minerals were smaller than 0.5) compared with those of $\mathrm{pH}$ and salt.

In order to focus on the effect of minerals on color formation, an additional PLS analysis was performed using the colored metabolites $\mathrm{E}$ and $\mathrm{F}$ and the three reverse color values as response variables. The model, 

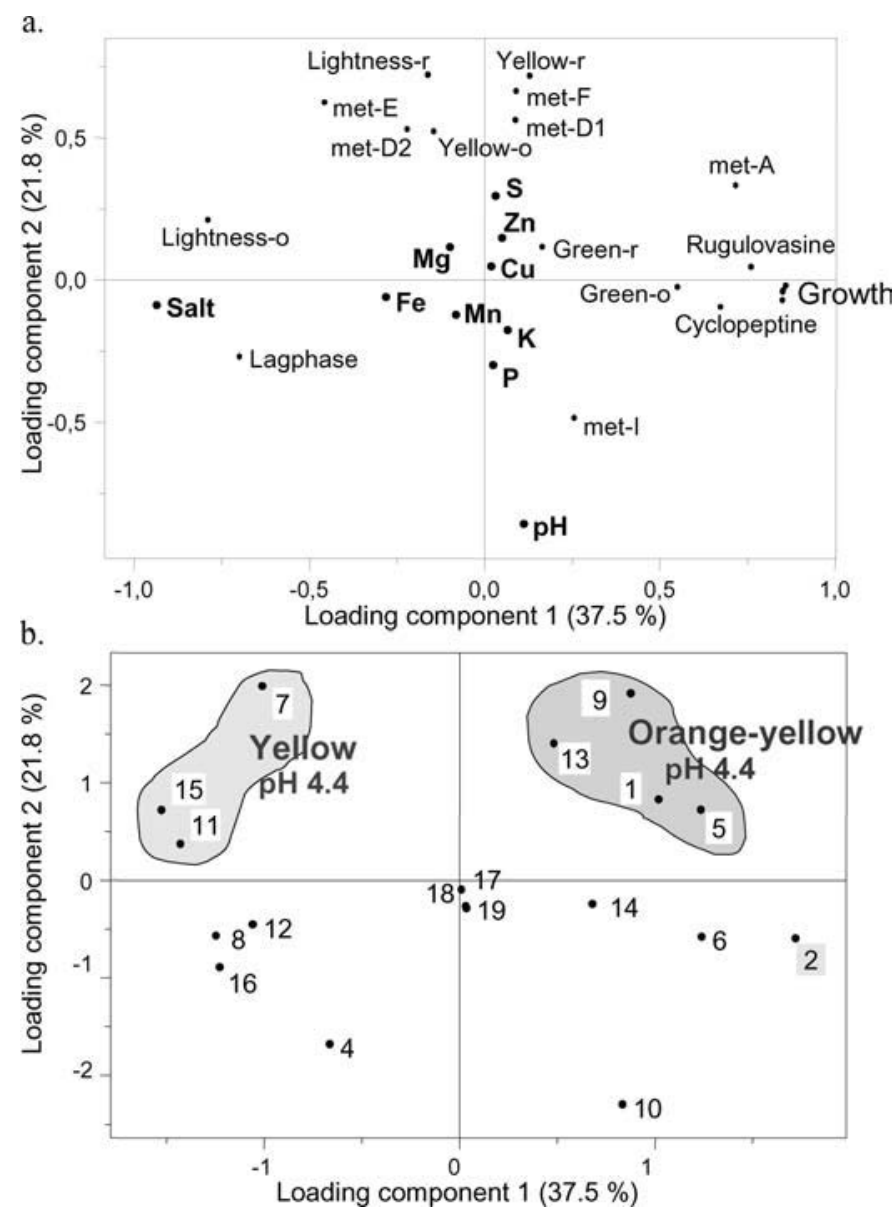

Figure 4. Loading (a) and scores (b) plot of the screening experiment of Penicillium caseifulvum (IBT 15157). The explained variance for each component is given in parenthesis, and the independent variables are shown in bold writing ( $\mathrm{S}$ was added to the analysis as an uncontrolled factor). The loading plot (a) shows that salt content of the media (Salt) was positively correlated with obverse lightness (Lightness-o) and lagphase (Lagphase), and negatively correlated with mold growth (Growth), obverse green color (Green-o), and production of metabolites A (met-A), rugulovasine (Rugulovasine), and cyclopeptine (Cyclopeptine). $\mathrm{pH}$ was positively correlated with production of metabolite I (met-I), and negatively correlated with reverse and obverse yellow color (Yellow-r, Yellow-o), reverse lightness (Lightness-r) and production of metabolites D1, D2, E, and F (metD1, met-D2, met-E, met-F). The scores plot (b) shows that some observations divided into groups according to visually observed color of the reverse colony side. The numbers identify sample number, which is identical to media number in the screening experiment (table 1).

which explained $73 \%$ of the variation with three loading components, exposed again the impact of $\mathrm{pH}$ on color formation, and showed that green color was not correlated to production of the colored metabolites $\mathrm{E}$ and F. Of the minerals the most important ones correlated with yellow color and colored metabolites were $\mathrm{P}, \mathrm{Mg}$ and $\mathrm{Cu}$. Consequently, these three minerals were used in a full factorial experiment to further analyze the

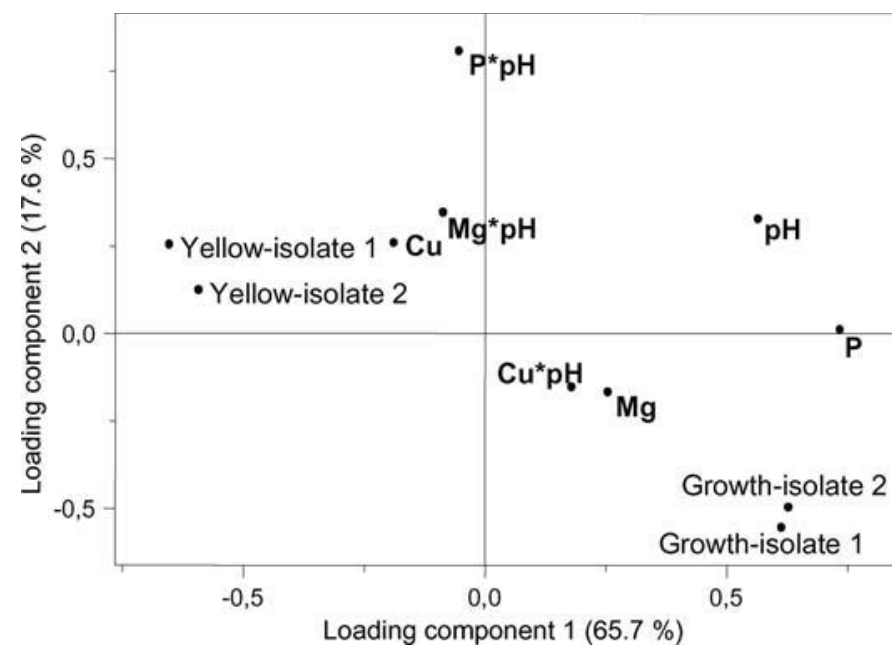

Figure 5. Loadings plot of the full factorial experiment. The explained variance for each component is given in parenthesis and the independent variables are shown in bold writing. Media $\mathrm{pH}(\mathrm{pH})$ (added to the analysis as an uncontrolled factor) and concentration of $\mathrm{P}(\mathrm{P})$ were the most significant factors for yellow color (Yellowisolate 1, Yellow-isolate 2) and growth (Growth-isolate 1, Growthisolate 2). High levels of $\mathrm{pH}$ or $\mathrm{P}(6000 \mathrm{mg} / \mathrm{kg})$ gave less yellow color, and increased growth.

mineral effect on yellow color development in $P$. caseifulvum colonies.

Growth of $P$. caseifulvum on media with different levels of $\mathrm{P}, \mathrm{Mg}$ and $\mathrm{Cu}$ showed only small differences in growth and morphology. After $14 \mathrm{~d}$ the average colony diameter for isolate 15151 and 15157 was $40.3 \pm 3 \mathrm{~mm}$ and $42.9 \pm 3 \mathrm{~mm}$, respectively. Yellow color measurements averaged $34.6 \pm 6.5$ and $30.7 \pm 7.2$ for isolate 15151 and 15157 , respectively.

Media containing high levels of $\mathrm{P}(6000 \mathrm{mg} / \mathrm{kg}) \mathrm{had}$, on average, a $1 \%$ higher $\mathrm{pH}$ value, equal to $0.05 \mathrm{pH}$ units, after autoclaving compared to media with low $\mathrm{P}$ content $(2000 \mathrm{mg} / \mathrm{kg})$. The difference in $\mathrm{pH}$ was significant by paired $t$-test $(P<0.05)$, and therefore $\mathrm{pH}$ was included as an additional factor in the data analysis. Minor variations of $\mathrm{pH}$ in all media were also recorded. The PLS model, explaining $72.9 \%$ of the variation with four components, showed that although the difference in $\mathrm{pH}$ was small (i.e. $5.10 \pm 0.01$ for low-P media and $5.15 \pm 0.03$ for high $\mathrm{P}$ media). The $\mathrm{pH}$ was significantly and negatively correlated with reverse yellow color, again confirming the importance of $\mathrm{pH}$ for yellow color development (Figure 5).

Of the minerals, $\mathrm{P}$ was the most important factor for yellow color and mold growth. High levels of P (6000 $\mathrm{mg} / \mathrm{kg}$ ) gave less yellow color and increased growth. It has previously been shown that $\mathrm{P}$ can be crucial for pathways in the secondary metabolism (Turner, 1971; Garraway and Evans, 1984). The results of this experi- 
ment suggest that $\mathrm{P}$ is important for metabolism that support mold growth but it inhibits metabolism causing yellow color formation. Thus, high levels of $\mathrm{P}$ may inhibit or reduce production of the colored metabolites $\mathrm{E}$ and $\mathrm{F}$.

The P-level in milk is reported to drop during the summer season (Larsen and Werner, 1985), coinciding with the period where pigmentation problems mostly occur. In conclusion, addition of phosphorous salts to the cheese-milk may prevent or reduce formation of pigments by contaminating molds. However, it may also increase the basis for mold growth.

In this experiment $\mathrm{P}$ was added as $\left(\mathrm{NH}_{4}\right)_{2} \mathrm{HPO}_{4}$, and since it was the only mineral added as an ammonia salt the effect of $\mathrm{P}$ and $\mathrm{N}$ could not be statistically separated. Therefore, future research on this subject should investigate the effect of $\mathrm{P}$ and $\mathrm{N}$ separately.

Similar to P, high levels of $\mathrm{Mg}(300 \mathrm{mg} / \mathrm{kg})$ were positively correlated with mold growth and negatively correlated with yellow color formation. In contrast, high levels of $\mathrm{Cu}(1.5 \mathrm{mg} / \mathrm{kg})$ were positively correlated with yellow color formation. Smith (1949) also showed that Penicillium implicatum production of the yellow pigment citrinin was induced when $\mathrm{Cu}$ was added to the growth media. However, the effect on yellow color formation was very small within the levels of $\mathrm{Cu}$ found in Blue Cheese (0.3 to $1.5 \mathrm{mg} / \mathrm{kg}$ ). This agrees with the fact that levels of $\mathrm{Cu}$ in milk used for Blue Cheese production are highest in the winter, but the yellow color formation is mostly a problem in the summer. Therefore, if high concentrations of minerals initiate yellow color formation in $P$. caseifulvum colonies, minerals other than $\mathrm{Mg}, \mathrm{Cu}$, or $\mathrm{P}$ are the cause. $\mathrm{Zn}$, for instance, may trigger yellow color formation, because it was positively correlated with yellow color formation (Figure 4a), and it is present in milk in highest levels during the summer (Larsen and Werner, 1985; von Kreuzer and Kirchgessner, 1990). Additionally, high levels of S (520 to $842 \mathrm{mg} / \mathrm{kg}$ ) were also positively correlated with yellow color (Figure 4a). However, S was not a controlled factor in this experiment.

\section{CONCLUSIONS}

Of the chromophores representing the majority of metabolites produced by $P$. caseifulvum in the different media, $\mathrm{E}$ and $\mathrm{F}$ were identified as the only colored products, i.e. greenish-yellow and orange-yellow, respectively. The production of these metabolites was also correlated with measurements of yellow color on the reverse side of mold colonies as well as visual observations.

Yellow pigmentation of $P$. caseifulvum colonies was induced at low $\mathrm{pH}$ (4). Even a very small decrease of
$\mathrm{pH}(0.1 \mathrm{pH}$ units $)$ in the media caused a significant increase in yellow color development. Thus, these findings stress the importance of controlling the $\mathrm{pH}$ in the Blue Cheese process.

Production of the colored metabolites was not affected by salt content or mold growth. Instead, increased salt content caused retardation of mold growth and increased the length of the lagphase.

Of the minerals, $\mathrm{P}$ was the only one that affected yellow color formation of the colonies. High levels of $\mathrm{P}(6000 \mathrm{mg} / \mathrm{kg})$ caused less yellow color development. Thus, the P-level may have a regulatory effect on production of the colored metabolites $\mathrm{E}$ and $\mathrm{F}$, and therefore addition of phosphorous salts to the cheese-milk may help prevent or reduce formation of yellow metabolites by P. caseifulvum on Blue Cheese. However, high levels of $\mathrm{P}$ also increased mold growth, which could limit the effectiveness of $\mathrm{P}$ added to the cheese-milk. This study could not identify any significant effects from any of the other minerals studied, i.e. $\mathrm{Mg}, \mathrm{Cu}, \mathrm{Mn}, \mathrm{Fe}$, and $\mathrm{S}$ (which was an uncontrolled factor).

Two of the seven chromophores that were analyzed were identified as rugulovasine and cyclopeptine, while the remaining metabolites were not identified. The seven chromophores were divided into three groups. One group consisted of metabolites related to mold growth, these were metabolite A, rugulovasine, and cyclopeptine. A second group consisted of colored metabolites produced at low $\mathrm{pH}$ (4 to 5); these were metabolites E, F, D1, and D2 (D1 and D2 were only slightly colored). Finally, a third group, consisting of just one metabolite, was produced at high $\mathrm{pH}$ (7); this was metabolite I.

\section{ACKNOWLEDGMENTS}

The support of the Danish Dairy Foundation (Danish Dairy Board) and the Danish Research and Development Programme for Food Technology is acknowledged.

\section{REFERENCES}

Chapman, H. R., and E. M. Sharpe. 1990. Microbiology of Cheese. Pages 157-243 in Dairy Microbiology. Vol. 2. R. K. Robinson, Elsevier Science Publishers, London.

Clutterbuck, P. W., A. E. Oxford, H. Raistrick, and G. Smith. 1932. Studies in the biochemistry of microorganisms. The metabolic products of the Penicillium brevi-compactum series. Biochem. J. 26:1441-1458.

Coni, E., A. Bocca, D. Ianni, and S. Caroli. 1995. Preliminary evaluation of the factors influencing the trace element content of milk and dairy products. Food Chem. 52:123-130.

Donnelly, W. J., and D. S. Horne. 1986. Relationship between ethanol stability of bovine milk and natural variations in milk composition. J. Dairy Res. 1:23-33.

Estrup, S. 1994. Microorganisms responsible for spoilage in ripened cheese. A review. Dairy Science and Technology, Hjørring, Denmark. 
Francis, F. J. 1985. Pigments and other colorants. Pages 545-584 in Food Chemistry. O. R. Fennema, Marcel Dekker, Inc., New York.

Frisvad, J. C., and U. Thrane. 1987. Standardized high-performance liquid chromatography of 182 mycotoxins and other fungal metabolites based on alkylphenone retention indices and UV-VIS spectra (diode array detection), J. Chromatogr. 404:195-214.

Garraway, M. O., and R. C. Evans. 1984. Fungal nutrition and physiology. John Wiley and Sons, Inc., New York, U.S.A.

Godinho, M., and P. H. Fox. 1981. Effect of NaCL on the germination and growth of Penicillium roqueforti. Milchwissenschaft. 36:205-208.

Grandison, A. S., G. D. Ford, A. J. Owen, and D. Millard. 1984. Chemical composition and coagulating properties of renneted Friesian milk during transistion from winter rations to spring grazing. J. Dairy Res. 51:69-78.

Griffin, D. H. 1994. Fungal Physiology. 2nd ed. Wiley-Liss, New York, U.S.A.

Haasum, I., and P. V. Nielsen. 1998. Ecophysiological characterization of common food-borne fungi in relation to $\mathrm{pH}$ and water activity under various atmospheric composition. J. Appl. Microbiol. 84:451-460.

Hermansen, J. E., S. Ostersen, and O. Aaes. 1994. Effect of the level of $\mathrm{N}$ fertilizer, grass and supplementary feeds on nitrogen composition and renneting properties of milk from cows at pasture. J. Dairy Res. 61:179-189.

von Kreuzer, M., and M. Kirchgessner. 1990. Zn, Fe, Cu und Mn in der Milch von Kuhen bei unterschiedlicher Rohproteinzufuhr. J. Anim. Physiol. Anim. Nutr. 63:204-209.

Larsen, J., and H. Werner. 1984. Calcium, magnesium, sodium, po tassium, phosphorus, chloride and iron in liquid milk products. 257th report. National Institute of Dairy Science, Hillerød, Denmark.

Larsen, J., and H. Werner. 1985. Heavy metals in market milk products. 262nd report. National Institute of Dairy Science, Hillerød, Denmark.

Lund, F. 1995. Penicillium solitum and a new Penicillium species causing discoloration of $P$. roqueforti fermented cheese. Pages 41-49 in Mycological methods for detecting the associated funga of cheese and ryebread in relation to hygiene. Ph.D. Diss., IBT, Technical University of Denmark, Lyngby, Denmark.
Lund, F., O. Filtenborg, and J. C. Frisvad. 1998. Penicillium caseifulvum, a new species found on fermented blue cheese. J. Food Mycol. 2:95-100.

Mariani, P., G. Zanzucchi, P. Blanco, and M. Masoni. 1993. Seasonal variations in the phosphorus content of bulk milk from individual dairy herds. Industria-del-Latte. 1:39-53.

Martin-Hernández, C., L. Amigo, P. J. Martin-Alvarez, and M. Juárez. 1992. Differentiation of milks and cheeses according to species based on the mineral content. Z. Lebensm. Unters. Forsch. 194:541-544.

National Food Agency of Denmark. 1989. Nutrient Composition of Danish Foods. Page 462 in Food Composition Tables. A. MØller, ed. Stougaard Jensen, Copenhagen, Denmark.

Northolt, M. D., and L. B. Bullerman. 1982. Prevention of mold growth and toxin production through control of environmental conditions. J. Food Prot. 6:519-526.

Northolt, M. D., J. C. Frisvad, and R. A. Samson. 1995. Occurrence of food-borne fungi and factors for growth. Pages 243-250 in Introduction to Food-Borne Fungi. 4th ed. R. A. Samson, E. S. Hoekstra, J. C. Frisvad, and O. Filtenborg, Centraalbureau voor Schimmelcultures, Baarn, Holland.

Piantanida, L., C. Cantoni, I. Dragoni, and A. Modolo. 1995. Alterazione gialla superficiale del Taleggio. Industrie Alimentari. 34:734-735.

Pitt, J. I. 1979. The genus Penicillium and its teleomorphic states Eupenicillium and Talaromyces. Acad. Press, London.

Samson, R. A., E. S. Hoekstra, J. C. Frisvad, and O. Filtenborg. 1995. Introduction to Food-Borne Fungi. 4th ed. Centraalbureau voor Schimmelcultures, Baarn, Holland.

Seitz, L. M., D. B. Sauer, R. Burroughs, H. E. Mohr, and J. D. Hubburd. 1979. Ergosterol as a measure of fungal growth. Phytopathology. 11:1202-1203.

Smith, G. 1949. The effect of adding trace elements to Czapek-Dox Medium. Trans. Br. Mycol. Soc. 32:280-283.

Turner, W. B. 1971. Fungal Metabolites. Acad. Press, London.

Wold, S., C. Albano, and W. J. Dunn III. 1984. Multivariate data analysis in chemistry. Pages 17-95 in Chemometrics: Mathematics and Statistics in Chemistry. B. R. Kowalski, ed., D. Reidel Publishing Company, Dordrecht, Holland. 